\title{
Interstitial nephritis associated with nivolumab in a patient with hodgkin lymphoma
}

\author{
(D) Deivide de Sousa Oliveira ${ }^{1}$ \\ (iD) Juliene Lima Mesquita ${ }^{2}$ \\ Yhasmine Delles Oliveira Garcia \\ (iD) Yensy Mariana Zelaya Rosales ${ }^{2}$ \\ (iD) Romélia Pinheiro Gonçalves Lemes ${ }^{2}$ \\ (iD) Francisco Dário Rocha Filho ${ }^{2}$ \\ Paula Frassinetti Castelo Branco Camurça Fernandes ${ }^{1}$ \\ (D) Pastora Maria Araujo Duarte 1 \\ (iD) Maria da Silva Pitombeira ${ }^{1}$ \\ (iD) Fernando Barroso Duarte ${ }^{1}$
}

1. Hospital Universitário Walter Cantídio - Fortaleza (CE), Brasil 2. Universidade Federal do Ceará - Fortaleza (CE), Brasil

http://dx.doi.org/10.1590/1806-9282.65.7.934

KEYWORDS: Nephritis, Interstitial. Hodgkin Disease. Immunotherapy.

\section{Dear editor}

A 19-year-old woman who had had advanced mixed cellularity Hodgkin's lymphoma (HL) since she the age of 11 was treated initially with a standard ABVD regimen (doxorubicin, bleomycin, vinblastine, and dacarbazine) with a complete response at the time; however, HL relapsed four years later, in 2011. We used an ICE regimen (ifosfamide, carboplatin, and etoposide) as salvage chemotherapy. Then, we performed high dose chemotherapy, followed by autologous stem cell infusion. After one year, her condition worsened again. We used brentuximab-vedotin (BV) in order to induce a response so that allogeneic transplantation would be feasible. After six cycles of brentuximab, the patient presented clinical signs of disease progression, such as lymph node enlargement, fever, cutaneous lesions, and weight loss. Anti-PD1 checkpoint inhibitor was administered to treat multi-refractory Hodgkin's lymphoma. After the first dose, symptoms subsided, and the patient was in excellent clinical condition.

After the sixth dose of nivolumab, she presented with generalized edema, respiratory distress, and pleural effusion at the radiological evaluation. The $24 \mathrm{~h}$ proteinuria was $36.0 \mathrm{~g}$ and serum albumin 2.5 $\mathrm{mg} / \mathrm{dl}$, configuring nephrotic range proteinuria. A renal biopsy was performed, which was compatible with lymphocytic interstitial nephritis (Fig. 1 and 2). A CT scan was performed, which showed new lymph node enlargement, configuring disease progression despite the checkpoint inhibitor. The anti-PD1 drug was interrupted, and the patient was closely evaluated to determine the response of urinary albumin loss 


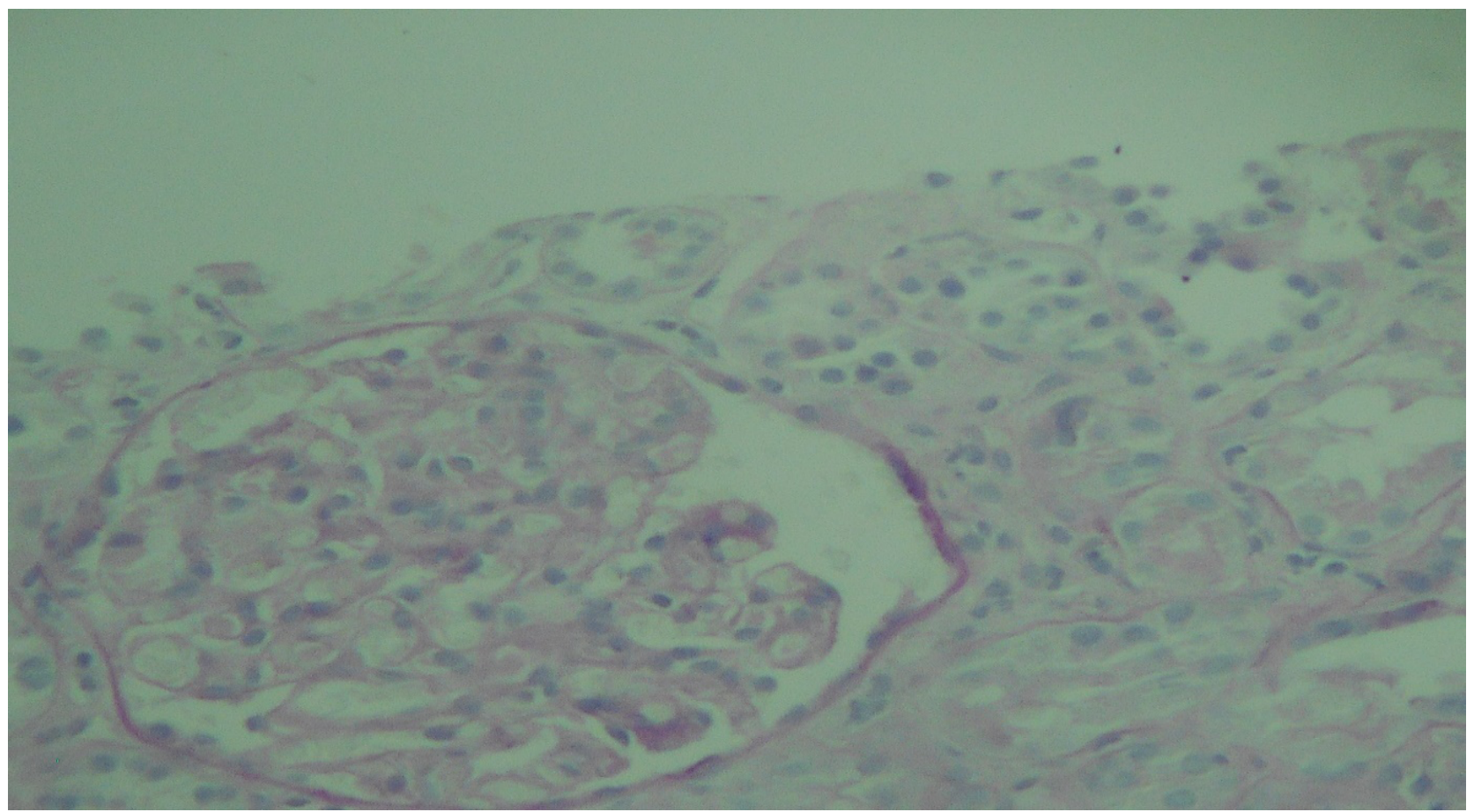

FIGURE 1. INTERSTITIAL NEPHRITIS (HEMATOXYLIN-EOSIN - HE 10OX)

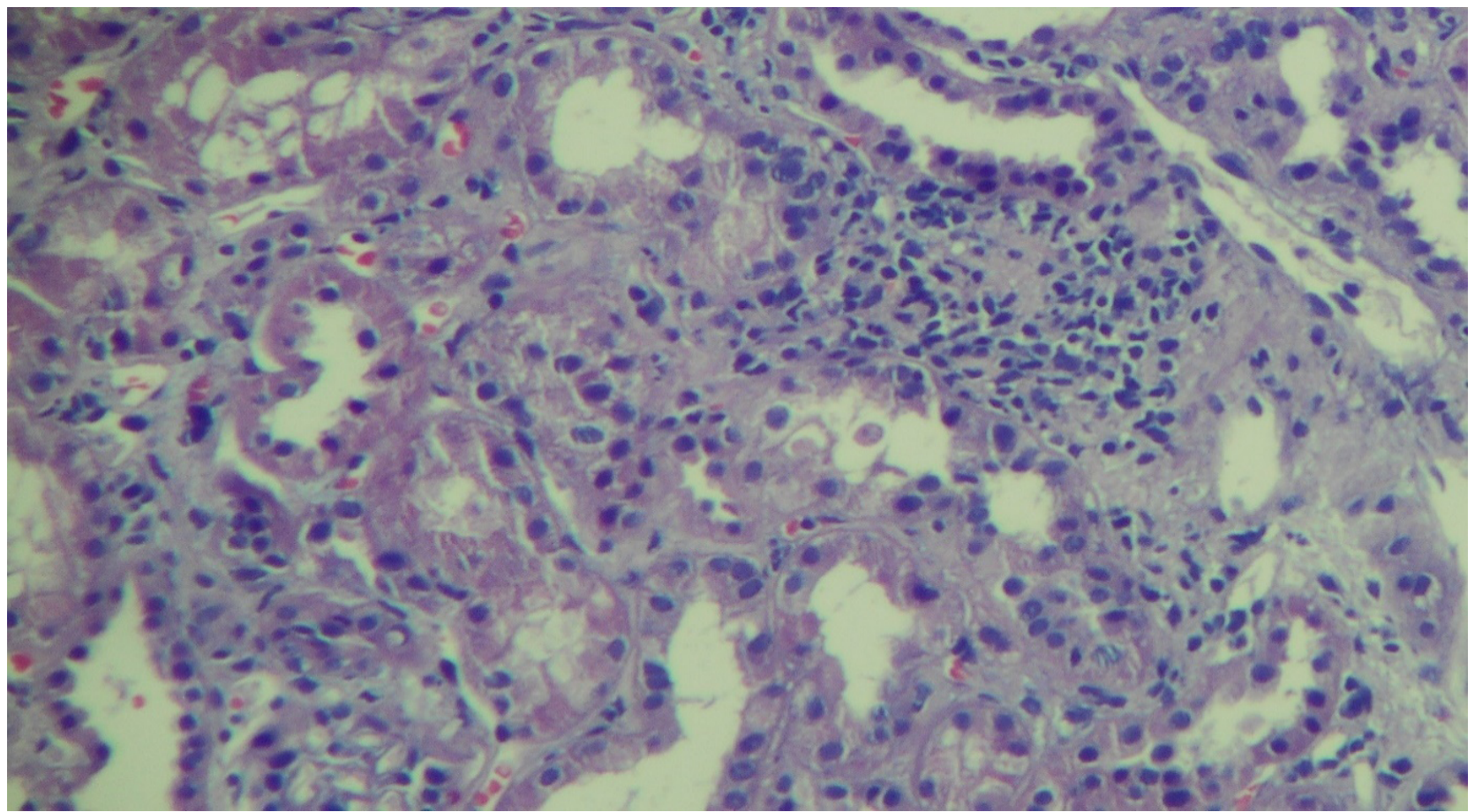

FIGURE 2. INCREASED CELLULARITY AND THE GLOMERULAR MATRIX (NEPHRITIS PERIODIC ACID-SCHIFF - PAS)

to corticotherapy (prednisone $1 \mathrm{mg} / \mathrm{kg} /$ day). Initially, we used angiotensin-converting enzyme inhibitors (captopril), diuretics (furosemide), and simvastatin to manage the nephrotic syndrome.

Lymph node enlargement decreased over time, proteinuria range fell to $200 \mathrm{mg} / 24 \mathrm{~h}$, and serum albumin increased from $2.5 \mathrm{mg} / \mathrm{dl}$ to $3.6 \mathrm{mg} / \mathrm{dl}$. There was no more edema, and drugs to control fluid wastage were stopped. We resumed nivolumab administration; currently, the patient has no sign of edema even with no antiproteinuric drugs, such as captopril and furosemide.

This new class of drugs can activate the immune response and facilitate the attack on neoplastic cells, 
especially in Hodgkin's lymphoma ${ }^{1,5}$. Unfortunately, this immune attack may be associated with loss of self-tolerance mechanisms. In this sense, there should be constant surveillance of patients using checkpoint inhibitors to detect the appearance of adverse immune reactions.

Kidneys are one of the sites of immune attack, especially in our report. There are many types of immune injury, such as glomerulonephritis, tubulointerstitial damage, and vasculopathy. The evaluation of proteinuria is important to define if the patient needs a biopsy to determine the causative pattern of the lesion. In our report the presence of nephrotic range proteinuria and the biopsy indicating lymphocytic damage allows us to link this presentation with the anti-PD1 drug. There are no standard indications of suspension and reintroduction guidelines in the context of adverse immune reactions.

We presented a successful reintroduction of the anti-PD1 drug after the adverse immune reaction. The pathophysiology background definition was very important to elucidate the pattern of damage and therapeutic options. We recommend that patients in use of anti-PD1 drugs presenting kidney function alteration be evaluated as soon as possible by a kidney biopsy.

\section{Conflict of interest}

The authors have no conflict of interest to declare.

PALAVRAS CHAVE: Nefrite Intersticial. Doença de Hodgkin. Imunoterapia.

\section{REFERENCES}

1. Timmerman $J M$, Engert $A$, Younes $A$, Santoro A, Armand P, Fanale MA, et al. Checkmate 205 update with minimum 12-month follow up: a phase 2 study of nivolumab in patients with relapsed/refractory classical Hodgkin lymphoma. Blood. 2016;128(22):1110.

2. Sharma P, Allison JP. The future of immune checkpoint therapy. Science. 2015;348(6230):56-61.

3. Younes A, Santoro A, Shipp M, Zinzani PL, Timmerman JM, Ansell S, et al.
Nivolumab for classical Hodgkin's lymphoma after failure of both autologous stem-cell transplantation and brentuximab vedotin: a multicentre, multicohort, single-arm phase 2 trial. The Lancet Oncol. 2016;17(9):1283-94.

4. Atanackovic D, Luetkens T. Biomarkers for checkpoint inhibition in hematologic malignancies. Semin Cancer Biol. 2018;52(Pt 2):198-206.

5. Merryman R, Armand P. Hodgkin lymphoma and PD-1 blockade: an unfinished story. Ann Lymphoma. 2017;1:4. 